\title{
Erratum to: Sex Differences in Cartilage Topography and Orientation of the Developing Acetabulum: Implications for Hip Preservation Surgery
}

\author{
Jonathan B. Peterson MD, Josh Doan MEng, James D. Bomar MPH, \\ Dennis R. Wenger MD, Andrew T. Pennock MD, Vidyadhar V. Upasani MD
}

Published online: 29 May 2015

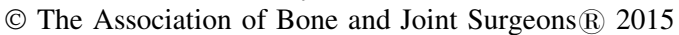

\section{Erratum to: Clin Orthop Relat Res DOI 10.1007/s11999-014-4109-5}

In the published study, "Sex Differences in Cartilage Topography and Orientation of the Developing Acetabulum: Implications for Hip Preservation Surgery" the units of measurement in reference to the surface area are incorrectly stated in several sections of the manuscript as " $\mathrm{mm}^{2}$ ". The units of measurement should be " $\mathrm{cm}^{2} "$.

In the second to last sentence in the Results section of the Abstract, the sentence should read "Articular surface area increased from 18 (8-10 years) to $24 \mathrm{~cm}^{2}$ (13-17 years) in males and from 17 (8-10 years) to $21 \mathrm{~cm}^{2}(13-17$ years) in females.

The title of Table 1 should read: "Table 1. Rate of increase $\left(\mathrm{cm}^{2} /\right.$ year $)$ in articular surface area of the acetabulum".

The title of Table 2 should read: "Table 2. Mean articular surface area $\left(\mathrm{cm}^{2}\right)$ ".
The first paragraph of the Results section misstated the units of measurement regarding the surface area eight times. The paragraph should read "The rate of increase in articular surface area between males and females was similar in the 8- to 10-year-old patient group $\left(1 \mathrm{~cm}^{2} /\right.$ year versus $1 \mathrm{~cm}^{2} /$ year). Males were increasing in articular surface area at a faster rate than females $\left(2 \mathrm{~cm}^{2} /\right.$ year versus $1 \mathrm{~cm}^{2} /$ year) in children aged 10 to 13 years. In the 13 - to 17 -year-old patient group, males continued to increase in articular surface area at a rate of $0.7 \mathrm{~cm}^{2} / y e a r$, whereas female patients were no longer experiencing increases in articular surface area in this age group (Table 1). Mean articular surface area was similar between males and females in the 8- to 10-year-old patient group (18 versus 17 $\left.\mathrm{cm}^{2} ; \mathrm{p}=0.421\right)$. Males had greater articular surface area in the 10- to 13-year-old patient group (22 versus $20 \mathrm{~cm}^{2}$; $\mathrm{p}<$ $0.001)$ and the 13- to 17 -year-old patient group (25 versus $21 \mathrm{~cm}^{2} ; \mathrm{p}<0.001$ ) (Table 2)."

The authors apologize for these errors.

The online version of the original article can be found under doi:10.1007/s11999-014-4109-5.

J. B. Peterson, J. Doan, J. D. Bomar, D. R. Wenger,

A. T. Pennock, V. V. Upasani $(\bowtie)$

Department of Orthopedic Surgery, Rady's Children's Hospital, 3030 Children's Way, Suite 410, San Diego, CA 92123, USA

e-mail: vupasani@rchsd.org 